\title{
Abia State HIV epidemic and response: challenges and prospects
}

\author{
Ugochukwu Uchenna Onyeonoro', Obiageli Fidelia Emelumadu², Uche Ngozi Nwamoh , Andrew \\ Ugwunna Ukegbu ${ }^{1}$, Godwin OC Okafor ${ }^{1}$ \\ ${ }^{1}$ Department of Community Medicine, Federal Medical Center, Umuahia, Abia State, Nigeria \\ ${ }^{2}$ Department of Community Medicine, Nnamdi Azikiwe University, Nnewi, Anambra State, Nigeria
}

\begin{abstract}
Since the first seroprevalence survey in 1999, the HIV prevalence in Abia State has increased from $1.8 \%$ to $7.3 \%$ in 2010 . The state is currently experiencing a generalized epidemic, with most transmission occurring through heterosexual low-risk sex. Drivers of the epidemic include low knowledge of HIV prevention, low risk perception, predominantly male factor-driven risky sexual behavior, and low condom use. This study reviewed the state HIV epidemic trend in relation to response, sought to identify the gaps between the epidemic and response, and recommended measures to strengthen the state response.
\end{abstract}

Key words: HIV/AIDS; epidemic; response; prevalence; behavior; Abia State.

J Infect Dev Ctries 2014; 8(11):1374-1377. doi:10.3855/jidc.4417

(Received 16 November 2013 - Accepted 24 July 2014)

Copyright (C) 2014 Onyeonoro et al. This is an open-access article distributed under the Creative Commons Attribution License, which permits unrestricted use, distribution, and reproduction in any medium, provided the original work is properly cited.

\section{Introduction}

Nigeria currently ranks third among countries with the highest number of people living with HIV/AIDS. HIV prevalence ranges between $1.0 \%$ and $12.7 \%$ among the 36 states in the country; Abia State is currently ranked $8^{\text {th }}$ with a HIV prevalence rate of $7.3 \%$ [1,2]. The state is currently experiencing a generalised epidemic, with transmission occurring mostly in the general population.

\section{Abia State HIV epidemiology}

HIV prevalence

Abia State is the only state in Nigeria that has witnessed a persistent rise in HIV prevalence among African National Congress attendees since 1999, increasing from $3.0 \%$ in 1999 to $7.3 \%$ in 2010 [3]. The national prevalence, on the other hand, increased from $1.8 \%$ in 1991 , peaked at $5.8 \%$ in 2001 , and declined to $4.1 \%$ in 2010 (Figure 1). The state general population prevalence increased from $1.6 \%$ in 2007 to $3.2 \%$ in 2012 , compared to a declining national prevalence from $3.6 \%$ to $3.4 \%$ in 2007 and 2010 , respectively [45]. There is significant urban-rural disparity in HIV prevalence in the state, with a higher prevalence reported in rural areas $(7.7 \%)$ than in urban areas $(2.7 \%)$ in 2005 . However, in 2010, a lower prevalence was observed in rural areas (3.0\%) than in urban areas $(9.0 \%)$ as shown in Figure 2. HIV prevalence among women between 15 and 24 years of age (which serves a proxy for new infections) declined from $7.3 \%$ in 2005 to $4.1 \%$ in 2008 and thereafter increased to $6.8 \%$ in 2010 (Figure 3), which suggests that the epidemic may likely escalate [3].

\section{Dynamics of HIV transmission}

Heterosexual transmission accounts for $80 \%$ of new infections; other modes of transmission including mother-to-child transmission account for the remaining 20\% [6]. Factors responsible for the rising HIV prevalence in the state include among others, low knowledge of HIV prevention (53.5\%), low personal risk perception $(<40 \%)$, multiple concurrent sexual partners (men, 18.8\%; women, $0.6 \%$ ), high rate of unprotected premarital sex among young people, low condom use (women, 32.2\%; men, 71.1\%), and persistence of economic and gender inequality [7-11]. Others are stigma and discrimination, poverty, increasing patronage of traditional healers, and absence of safe blood transfusions [12].

The role of most-at-risk populations (MARPs)

Geographic mapping of MARPs in the state showed 87, 5, and 3 active spots, and an estimate of 1,661, 324, and 20 for female sex workers (FSWs), men having sex with men (MSM) and intra-venous drug users (IDUs), respectively [13]. An earlier 
national survey revealed low knowledge of HIV prevention methods (41\%) and low level of comprehensive knowledge of HIV/AIDS (12\%) among FSWs in the state, as well as multiple concurrent sexual partners, low condom use (89\%), high prevalence of sexually transmitted infections $(15 \%)$, and poor care-seeking behaviour [14]. Also, use of traditional medicine and charms, alcohol and drug use, participation in religious activities, and careful selection of clients were identified as measures adopted by sex workers to protect themselves [15].

\section{The state's response to the HIV epidemic}

Until 2005, there was no coordinated HIV response in the state, as response to HIV was an individual's responsibility. The state's HIV response commenced in 2005 upon recognition of HIV as a threat to development, hence its inclusion in the state development strategy [16]. Following this, the Abia State Action Committee on AIDS was established to coordinate the state multi-sectorial response and development of the first state HIV/AIDS strategic plan [17]. The response intensified following transformation of the committee into the Abia State Agency for the Control of AIDS in 2010, alongside development of more state-specific policy documents - the second State HIV/AIDS Strategic Plan [3], the State Prevention Plan (SPP) [6], and the State Monitoring and Evaluation Plan [18] - and adoption of relevant national documents/guidelines for guidance on HIV interventions. Local government action committees on AIDS (LACAs) were established in all the 17 Local Government Areas (LGAs) to drive the response at the community level. Several healthcare and non-healthcare workers were trained on the provision of HIV services at both facility and community levels. Activities of implementing partners working in the state were streamlined in order to avoid duplication of efforts and promote efficient utilization of resources. Furthermore, economic and geographic barriers to HIV services were addressed through provision of free HIV services and establishment of additional service delivery points. Also, stigma and discrimination have been declining at facility, institutional, and community levels as a result of several strategic behavior change communication interventions implemented in the state.
Figure 1. HIV prevalence trend in Abia State and Nigeria (1991-2010)

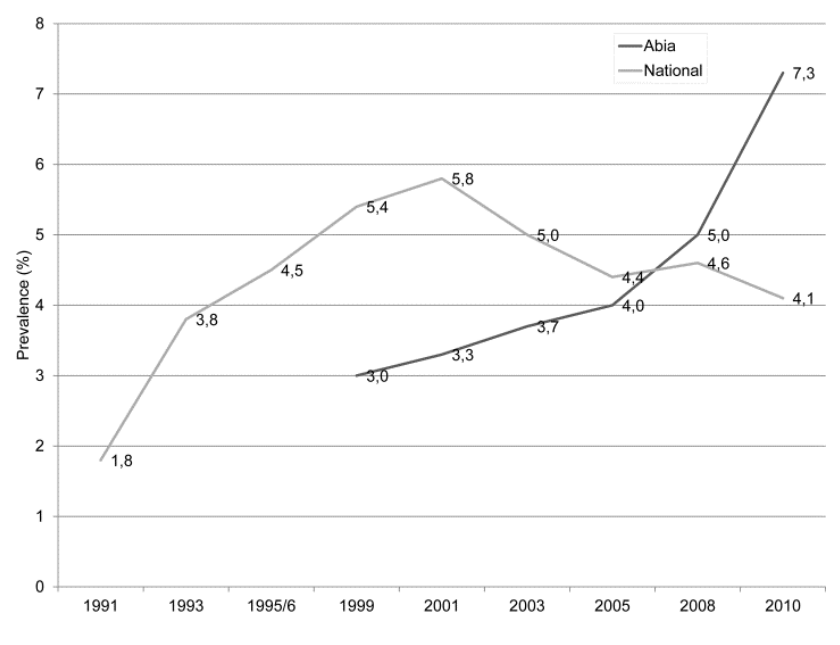

Figure 2. HIV prevalence in urban and rural areas in Abia State (2005-2010)

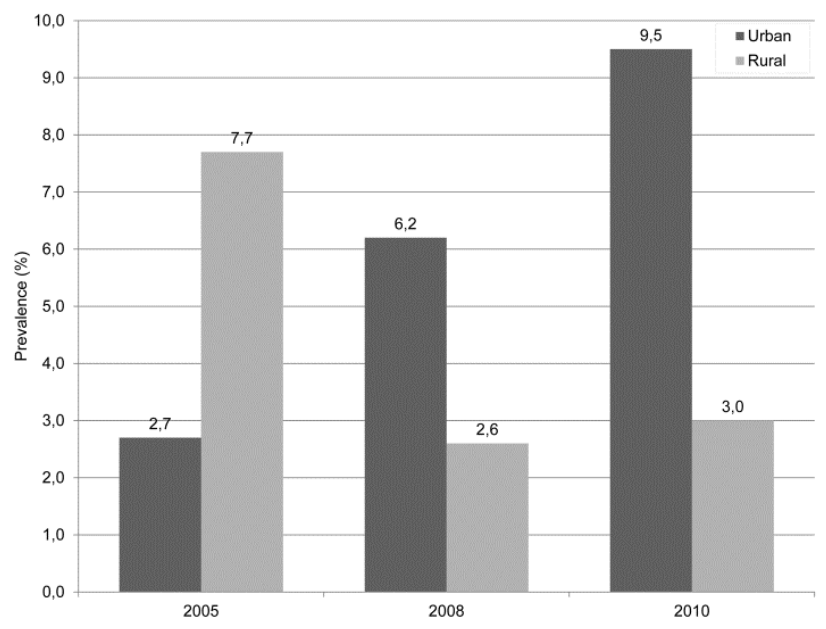

Figure 3. HIV prevalence among young pregnant women (15-24 years of age) in Abia and Nigeria (2005-2010)

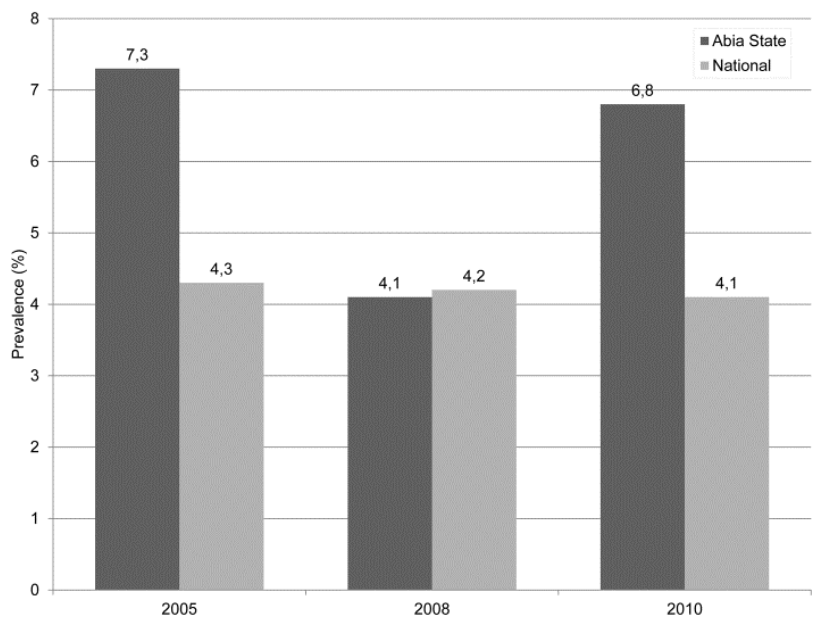




\section{How adequate are HIV resources in the state?}

Since the transformation of Abia State Action Committee on AIDS into an agency (Abia State Agency for the Control of AIDS) in 2010, the capacity of the establishment to coordinate the state response has increased significantly in terms of staffing and infrastructure; however, there is still a need to improve the competence of the staff of the agency on HIV program management. The implementation of the state response is divided into a public sector and a private sector response. The public sector response is implemented through the seven line ministries and LACAs, while the private sector response is implemented through civil society organizations/nongovernmental organizations and private organizations. For about a decade, the World Bank has been supporting the state response through the provision of grants and training, as well as through establishing and strengthening HIV coordination mechanisms. Eighty percent of the response is health-related and is housed in the State Ministry of Health, coordinated by the State AIDS/STIs Control Programme Unit. Their primary responsibilities include the training of healthcare providers on HIV services, management of HIV commodities, and monitoring and evaluation. The State Ministry of Education implements the Family Life HIV/AIDS Education among in-school youths, and has so far covered $21.1 \%$ and $24.8 \%$ of the students and schools targeted, respectively [19]. Key sources of HIV funding in the state are the World Bank, the Global Fund and the President's Emergency Plan for AIDS Relief (PEPFAR); however additional financial resources are required to meet the state targets. Financial support from the state government is low, though this does not often take into consideration the money spent on personnel emoluments and physical infrastructure. Also, private sector contribution is low and the only significant privatesector-led initiative in the State is the Niger Delta AIDS Relief project funded by Shell Petroleum Development Company [8].

\section{How comprehensive is the scope of HIV services coverage in the state?}

By the end 2013, the number of prevention of mother-to-child transmission (PMTCT), HIV counselling and testing (HCT), and antiretroviral treatment (ART) service delivery outlets in the state was 256 and 24, respectively. These facilities are technically supported either by Family Health International 360 or the Planned Parenthood
Federation of Nigeria and are funded through PEPFAR and the Global Fund, respectively [20].

Current prevention interventions are implemented using the minimum prevention package interventions approach, unlike in the past when they were mainly bio-medically oriented, not linked with behavioral and structural factors, and were rarely focused on specific target populations. HCT service coverage currently stands at $12.1 \%$, while ART service coverage increased from $25 \%$ in 2009 to $42.6 \%$ in 2013 despite increasing HIV prevalence and adjustment in eligibility criteria (from less than $200 \mathrm{CD} 4$ cells to 350 CD4 cells). PMTCT coverage has been fluctuating; it increased from $19 \%$ in 2009 to $66.6 \%$ in 2012 and declined to $39.4 \%$ in 2013 [20]. Tuberculosis (TB)/HIV services detected $21 \%$ co-infected individuals among 1,421 TB patients in 2013. A major weakness in HIV services is the low coverage of care and support services such as isoniazid preventive treatment, cotrimoxazole preventive treatment, and care of orphans and vulnerable children.

\section{How effective are the HIV interventions in the state?}

Although implementation of HIV interventions in the state is based on globally accepted standards, the response has not kept pace with the epidemic. A review of the first strategic plan in 2010 revealed that the state failed to attain its objective of reducing the prevalence from $3.7 \%$ in 2005 by $40 \%$ in 2010 ; rather, it rose to $7.3 \%$ [16]. Reasons for this could be poor alignment of intervention efforts to drivers of the epidemic and low service coverage. Most service outlets are located in urban areas; hence, the majority of the rural residents (which account for $60 \%$ of the population) do not have access to them. There is a failure to target specific populations with appropriate interventions because state HIV data is not segregated by locality, gender, and age. Also, there are no statespecific data on MARPs behaviors, so these groups are not effectively targeted [6]. Finally, there is a paucity of operational research to help identify opportunities and constraints or barriers in HIV programming in the state.

\section{Conclusions}

It is evident that the state has made some progress in its HIV response in the form of improved coordination and increased HIV services coverage, among others. However, the state still needs to increase its funding of HIV services, expand service coverage, and increase generation of evidence through 
operational research to improve HIV program implementation with the goal of significantly reducing the prevalence of HIV/AIDS in Abia State, Nigeria.

\section{References}

1. Federal Ministry of Health (2010) National HIV Seroprevalence Sentinel Survey Among Pregnant Women Attending Antenatal Clinics in Nigeria. Abuja, Nigeria: Federal Ministry of Health.

2. National Agency for the Control of AIDS (2012) Global AIDS Response Country Progress Report. Abuja, Nigeria: NACA.

3. Abia State Agency for the Control of AIDS (2010) Abia State HIV/AIDS Strategic Plan 2010 - 2015. Umuahia: Abia State Agency for the Control of AIDS.

4. Federal Ministry of Health (2008) National HIV/AIDS and Reproductive Health 2007 Survey, (NARHS Plus). Abuja, Nigeria: Federal Ministry of Health.

5. Federal Ministry of Health (2013) National HIV/AIDS and Reproductive Health Survey, 2013 (NARHS Plus). Abuja, Nigeria: Federal Ministry of Health.

6. Abia State Agency for the Control of AIDS (2012) Abia State HIV Prevention Plan 2012 - 2014. Umuahia: Abia State Agency for the Control of AIDS.

7. National Population Commission and ICF Macro (2009) Nigeria Demographic and Health Survey 2008. Abuja, Nigeria: National Population Commission (NPC) and ICF Macro.

8. Abia State Agency for the Control of AIDS (2009) Abia State HIV/AIDS Epidemiology Response, Policy Synthesis (ERPS). Umuahia: Abia State Agency for the Control of AIDS.

9. Smith DJ (2007) Modern marriage, men's extramarital sex, and HIV risk in southeastern Nigeria. Am J Pub Health 97: 997-1005.

10. Izugbara CO (2001) Tasting the forbidden fruit: The social context of sexual debut among young persons in a rural Nigerian community. Afr J Reprod Health 5: 22-29.

11. Oshi SN, Ezugwu FO, Oshi DC, Dimkpa U, Korie FC, Okperi BO (2006) Does self-perception of risk of HIV infection make the youth to reduce risky behaviour and seek voluntary counseling and testing services? A case study of Nigerian youth. J Soc Sci 14: 195-203.

12. Enwereji EE (2008) Important medicinal plants for treating HIV/AIDS opportunistic infections in Nigeria. Middle East Journal of Family Medicine 20: 21-28.

13. Society for Family Health (2013) Geographic Mapping of Population of Most at Risk Population (MARPs) in Abia State (2012). Umuahia: Society for Family Health.

14. Federal Ministry of Health (2000) Behavioural Surveillance Survey (BSS). Abuja, Nigeria: Federal Ministry of Health.

15. Izugbara CO (2005) 'Ashawo suppose shine her eyes': Female sex workers and sex work risks in Nigeria. Health, Risk \& Society 7: 141-159.

16. Abia State Planning Commission (2005) Abia State Economic Empowerment and Development Strategy (ABSEEDS). Umuahia: Abia State Planning Commission.

17. Abia State Agency for the Control of AIDS (2007) Abia State HIV/AIDS Strategic Plan 2007 - 2010. Umuahia: Abia State Agency for the Control of AIDS.

18. Abia State Agency for the Control of AIDS (2012) Abia State HIV Monitoring and Evaluation Plan 2012 -2014. Umuahia: Abia State Agency for the Control of AIDS.

19. Abia State Ministry of Education (2013) Annual HIV Report. Umuahia: Abia State Ministry of Education.

20. National Agency for the Control of AIDS (NACA) (2013) National Validated Health Service Data Report. Abuja: National Agency for the Control of AIDS.

\section{Corresponding author}

Ugochukwu Uchenna Onyeonoro

Consultant Public Health Physician/Epidemiologist

Department of Community Medicine, Federal Medical Center Umuahia, Abia State, Nigeria.

P.O Box 73, Ubakala,

Umuahia, Abia State

Phone:+234-803-8726960

Email: u2onyeonoro@gmail.com

Conflict of interests: No conflict of interests is declared. 